\title{
Equine Thymocyte Immune Globulin
}

National Cancer Institute

\section{Source}

National Cancer Institute. Equine Thymocyte Immune Globulin. NCI Thesaurus. Code C80824.

A purified, concentrated and sterile solution of horse-derived gamma globulin obtained by the immunization of horses with human $\mathrm{T}$-lymphocytes, with $\mathrm{T}$-cell depleting and immunosuppressive activities. Upon administration, horse anti-thymocyte globulin (hAT G) specifically recognizes, modulates and destroys T-lymphocytes. Although the exact mechanism of action by which hAT G causes immunosuppression is not completely understood, it is likely caused by a combination of T-lymphocyte depletion, reduction in T-cell activation and modulation of their cytotoxic activities. Administering of hAT G prior to transplantation may reduce the risk of graft-versus-host disease (GvHD). 